\title{
Effects of Improving Durability of Concrete by AQUA CURTAIN Curing and Its Application - Development of the New Wet Curing Method
}

\author{
Yukinori Furukawa ${ }^{1}$, Kazuto Fukudome ${ }^{1}$ and Yasuhiro Mitani ${ }^{2}$ \\ 1. Civil Engineering Division Hazama Corporation, Tokyo, Japan \\ 2. Department of Civil and Structural Engineering, Graduate School of Engineering, Kyushu University, Fukuoka, Japan
}

\begin{abstract}
We report a wet curing system developed and made suitable for practical application to curing the interior and vertical concrete surfaces of tunnel linings after the formwork has been removed. In this system, air is evacuated from the gap between the curing sheet and the concrete surface to create a close contact, and by supplying water to the space between the contacting surfaces, a water film is formed over the concrete surface. This enables the wet curing of vertical concrete surfaces and interior surfaces of tunnel linings after the formwork has been removed, a process that has to date been difficult. In this paper, the effects of wet curing on improving the durability of concrete are verified, and examples of the application of wet curing to actual structures are presented.
\end{abstract}

Key words: Wet curing, freeze-thaw resistance, carbonation resistance, pore structure, tunnel lining concrete.

\section{Introduction}

In the fabrication of concrete constructions, curing is one of the most important processes for optimizing the performance of concrete.

In order to obtain the desired concrete performance and to ensure durability, such as strength and mass-transfer resistance, it is important to hydrate cement properly. Therefore, it is crucial to maintain the appropriate temperature and moisture level required for hydration for the necessary period. However, while it is easy to supply moisture to a horizontal surface, where ponding or a curing mat soaked with water can be used, it is extremely difficult to apply curing to a vertical surface. Therefore, at an actual construction site, curing is likely to cease before the completion of the curation period necessary for hydration.

To remedy this, the authors have developed a novel wet curing system, called AQUA CURTAIN (AC), that enables the supply of curing water from the outside

Corresponding author: Yukinori Furukawa, research field: civil engineering. E-mail: furukawa@hazama.co.jp. to the interior and vertical concrete surfaces of tunnel linings after the formwork has been removed [1].

This paper details the Japanese specifications relevant to curing and provides an overview of the $\mathrm{AC}$ system. In addition, we present the findings of a quantitative test conducted to ascertain the effects of the curing method. Finally, examples of the system's application to actual structures are described.

\section{Specifications Related to Concrete Curing}

According to the American Concrete Institute Committee 308 [2, 3] (ACI), specific degrees of moisture and temperature - crucial factors for hydration - are necessary for concrete curing.

In Japan, the period for wet curing is specified in the standard specifications set forth by the Japan Society of Civil Engineers (JSCE) [4] and those by the Architectural Institute of Japan (AIJ) [5]. On the basis of these standards, the definition of wet curing is summarized below.

The JSCE lists the same curing methods for maintaining wet conditions as the ACI. These methods 
include the following: in water, ponding, spray curing, covering with a wet cloth (preferably a curing mat), wet sand, and membrane curing. Wet curing is defined as a type of curing that "is conducted not only to prevent the water required for hydration from dissipating from the poured concrete, but also to ensure that only the necessary amount of water is retained."

The curing methods for maintaining moistness are specified in the AIJ as by the JSCE. These methods include curing using a sheathing board with low permeability, for which they state that "sheathing board retention may be considered a form of wet curing."

According to the Recommendation for Practice of Hot Weather Concreting published by the Architectural Institute of Japan [6], concrete curing is, in principle, conducted by supplying water from the outside. However, if such curing is not practical, the next best method, such as using a curing agent or sheet curing, should be used.

The curing periods specified by JSCE and AIJ are shown in Tables 1-2, respectively. Both standards indicate almost the same curing period, and stipulate that wet curing is required for concrete curing and moisture is important for this method. However, the method for retaining moisture and the amount of water required to be retained are not stated.

\section{Overview of the AQUA CURTAIN Curing System}

\subsection{Status of System Development}

Wet curing, which not only prevents moisture dissipation but also actively supplies water from the outside, has a significant effect on the performance of concrete. However, it is difficult to conduct perfect wet

Table 1 Curing periods (JSCE) [4].

\begin{tabular}{llll}
\hline Dailymean & $\begin{array}{l}\text { Ordinary } \\
\text { Portland } \\
\text { cement }\end{array}$ & $\begin{array}{l}\text { Blended cements High-early-str } \\
\text { (Blast furnace slag ength Portland } \\
\text { cement[typeB]) }\end{array}$ & cement \\
\hline$\geqq 15^{\circ} \mathrm{C}$ & 5 days & 7 days & 3 days \\
$\geqq 10^{\circ} \mathrm{C}$ & 7 days & 9 days & 4 days \\
$\geqq 5^{\circ} \mathrm{C}$ & 9 days & 12 days & 5 days \\
\hline
\end{tabular}

Table 2 Wet curing periods (AIJ) [5].

\begin{tabular}{|l|l|l|}
\hline Cement type & $\begin{array}{l}\text { General/sta } \\
\text { ndard }\end{array}$ & Long-term \\
\hline High-early-strength Portland cement & $\geqq 3$ days & $\geqq 5$ days \\
\hline Normal Portland cement & $\geqq 5$ days & $\geqq 7$ days \\
\hline Other cements & $\geqq 7$ days & $\geqq 10$ days \\
\hline
\end{tabular}

curing on a construction site, particularly the application of wet curing to vertical and inclined surfaces after the formwork has been removed. The developed AC system forms a water film on the concrete surface, including vertical walls of structures and interior surfaces of tunnel linings, and ensures that an appropriate wetness condition is maintained.

A. M. Neville categorizes curing methods as methods for supplying water to concrete and those for preventing water loss from concrete, called "wet curing" and "membrane curing" respectively. In addition, the principles of each curing method need to be considered [7].

Fig. 1 shows the diagram of Neville's categorization as modified for application to the AC curing method.

\subsection{Construction Technique for AC Curing}

\subsubsection{System Configuration}

This system consists of a curing sheet, suction equipment, and water supply equipment. A schematic of the system and its section when AC is applied to a vertical wall are shown in Figs. 2-3. The system evacuates air from the gap between the curing sheet and the concrete surface using suction equipment to create decompression, which brings the curing sheet in close contact with the concrete surface. Water is then supplied between the contacting surfaces to form a water film over the concrete surface.

\subsubsection{Construction Process}

The curing construction process is described below.

The formwork, support members, and binding wires are removed.

A water supply hose is positioned at the upper part of the concrete surface and a curing sheet is temporarily attached. 


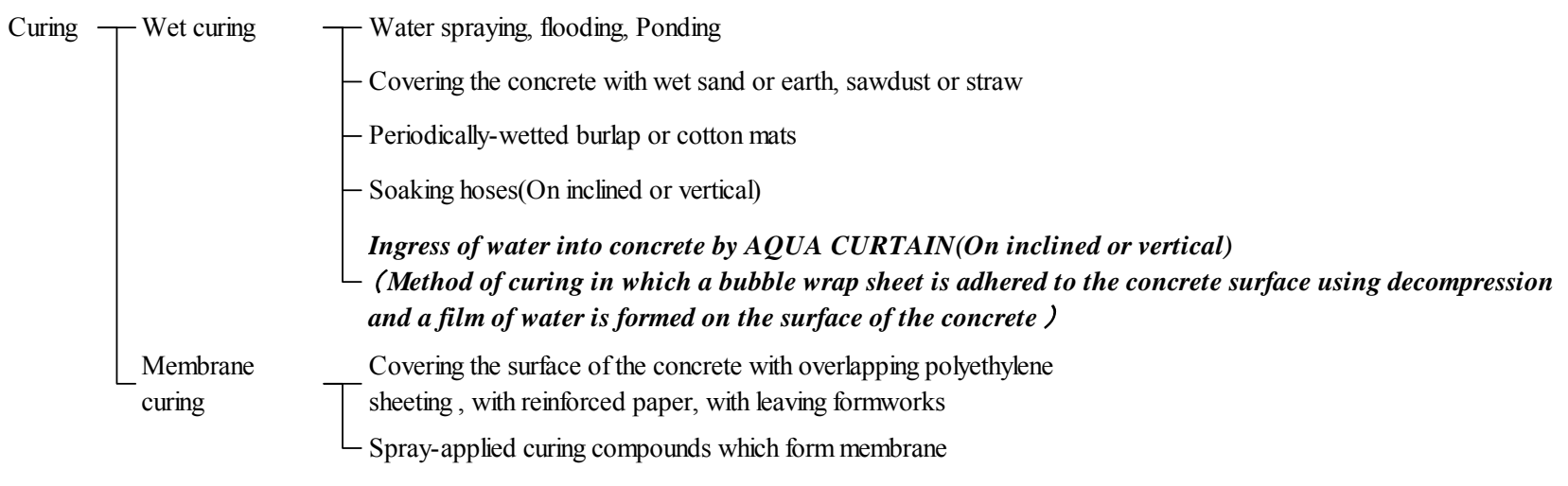

* Italics indicate the amendments made by the authors to Neville's paper.

Fig. 1 Categories of curing (Modified [7]).

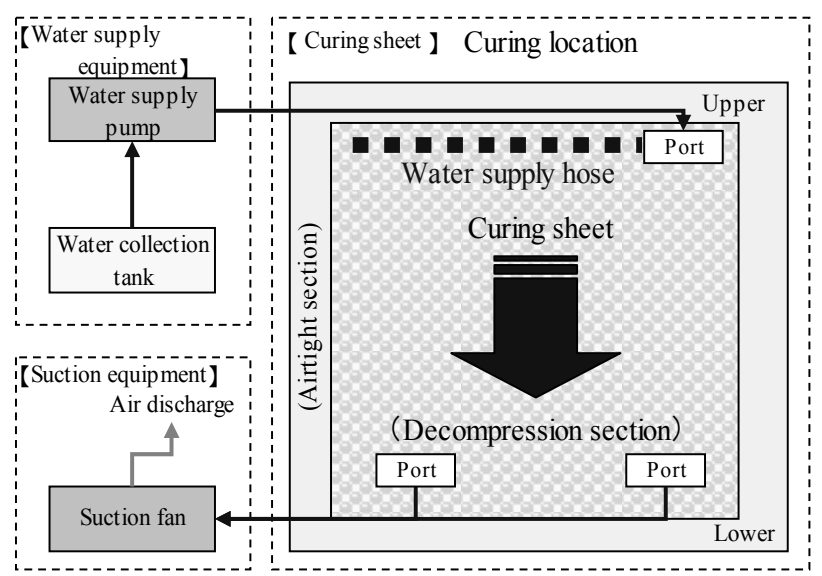

Fig. 2 Schematic diagram of AC system.

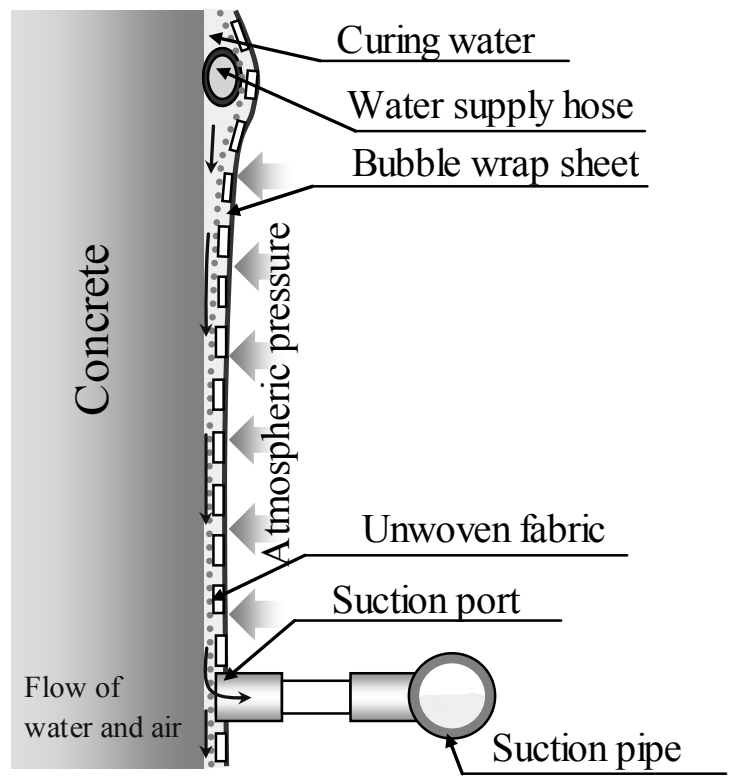

Fig. 3 AC system section at curing location.

Suction ports are positioned at the bottom of the curing sheet at intervals of approximately $4 \mathrm{~m}$.
The suction equipment and the suction pipe are connected.

After ensuring that the edges of the curing sheet are airtight, the suction fans are activated.

A supply of curing water from the water supply hose connected to the water supply pump is initiated to start the wet curing process.

\subsubsection{Regulation of Water Supply}

The water supply is regulated so that a specified amount of water is supplied intermittently from the start to the end of the curing process in accordance with the water absorption rate of the concrete. Points to note are described below.

The amount of water supply required is determined by ascertaining the amount required to wet the entire surface of the applicable concrete area.

The intervals between each water supply session are determined so that the concrete surface does not dry out, and these intervals are determined depending on the actual conditions at the construction site.

\subsection{Main Equipment}

\subsubsection{Curing Sheet}

Two types of material are used for the curing sheet: material having an uneven surface, used for the decompression section, and that having a smooth surface, used for the airtight section. The features of the curing sheet are described below. 


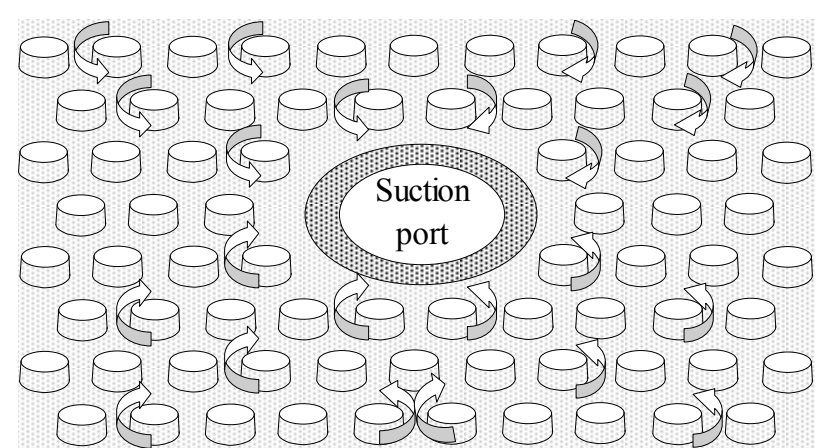

Fig. 4 Securing the air flow path by using a curing sheet with an uneven surface.

In order to expand the decompression area, it is important to secure an adequate air flow. Therefore, an uneven sheet surface is required, as shown in Fig. 4.

Bubble wrap is used for the curing sheet, because it is lightweight, inexpensive, and has good heat-retention properties.

The water holding capability of the sheet can be improved by attaching hydrophilic unwoven fabric to the surface of the concrete covered with the bubble wrap.

\subsubsection{Suction Fan and Water Supply Pump}

A turbo fan is used to maintain a stable suction rate for a long period. While deciding the specifications of the turbo fan, the curing area should be considered and a fan that can maintain the necessary air flow rate and air pressure for that area should be chosen.

With respect to the specifications of the pump used for supplying the curing water, the height of the pump head should be adequate enough to reach from the water collection tank to the water supply hose.

\subsubsection{Water Supply Hose}

The water supply hose should be approximately $70-100 \mathrm{~m}$ long.

\section{Effects of AC Wet Curing}

\subsection{Purpose and Overview of Tests}

To ascertain the effects of wet curing, the authors investigated the impact of wet curing on the development of the compression strength of normal Portland cement. It was found that wet curing improved the compression strength over an extended period [8]. However, not only strength but also mass-transfer resistance relating to durability is important in attaining the expected performance of concrete.

Okazaki et al. conducted strength tests, water absorption tests, and air permeability tests on specimens created under different curing conditions, and performed a quantitative assessment of the effect of different curing methods on the strength and mass-transfer resistance of concrete [9].

The tests results showed that there was a clear correlation between hydration rate and compression strength, but the mass-transfer resistance obtained from the water absorption test and air permeability test varied according to the differences in curing methods.

On the basis of these results, Okazaki et al. concluded that with respect to mass-transfer resistance, the permeability of concrete is determined mainly by the continuity of the pore structure rather than the number of pores and the hydration rate.

In this study, in order to investigate the effect of wet curing on durability, freeze-thaw resistance, carbonation resistance, and pore size distribution tests were conducted to evaluate mass-transfer resistance quantitatively.

The mix proportions for the concrete used are shown in Table 3. The cement used included normal Portland cement $(\mathrm{N})$ and Portland blast furnace slag cement (BB). In addition to simulations run using general structures, a simulated case (BT) using tunnel lining concrete that had the formwork removed at an earlier stage than usual and on which it is difficult to apply wet curing was conducted. The target values for slump and air volume at the time of pouring the concrete were $8 \pm 2.5 \mathrm{~cm}$ and $4.5 \% \pm 1.5 \%$, respectively.

Details of the curing conditions are shown in Table 4. As mentioned previously, it has not been clarified in Japan as to whether curing using sheathing board retention is considered to be wet curing, but it is expressed as membrane curing in this table in accordance with Neville's categorization. 


\subsection{Effects on Freeze-Thaw Resistance}

A freeze-thaw resistance test was conducted using normal Portland cement according to Method A of JIS A 1148, which is similar to ASTM C 666(A), and the material age at the start of the test was 28 days. A freeze-thaw resistance test on a test specimen that was subjected to air curing, but not water curing, was conducted immediately after measuring the initial value when the specimen was taken from a temperature- and humidity-controlled room without having absorbed any water. Measurements were performed once every 30 cycles up to 300 cycles.

The relationship between freeze-thaw cycles and relative dynamic modulus of elasticity is shown in Fig.5.

The symbols in Fig. 5 indicate the curing methods shown in Table 4. The reduction in the relative dynamic modulus of elasticity associated with the freeze-thaw cycles decreases with the curing period.
This is because the specimen becomes progressively drier with decreasing curing period; the degree of saturation is low and the specimen is less susceptible to deterioration resulting from freeze thaw.

The calculation results of the dynamic modulus of elasticity based on the number of resonant vibrations and the test specimen mass according to JIS A 1127 are shown in Fig. 6.

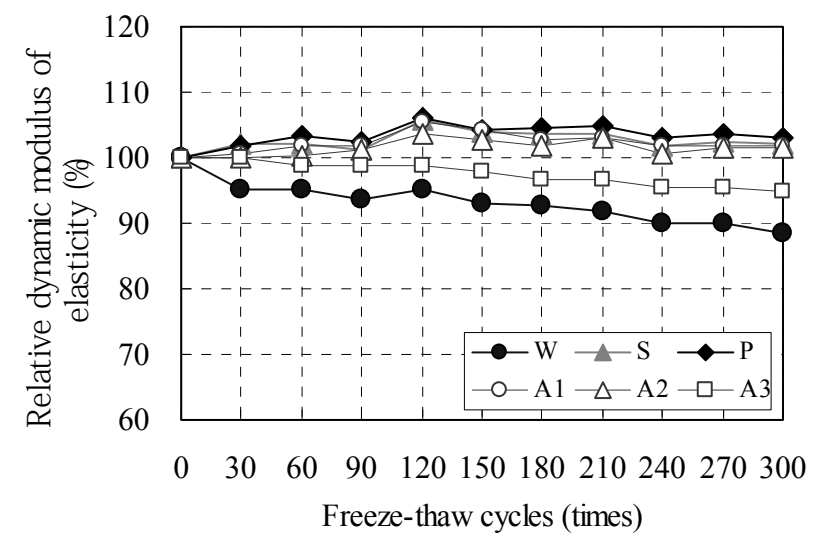

Fig. 5 Relationship between freeze-thaw cycles and relative dynamic modulus of elasticity.

Table 3 Mix proportions.

\begin{tabular}{|c|c|c|c|c|c|c|c|c|}
\hline \multirow{3}{*}{ Symbol } & \multirow{3}{*}{$\mathrm{W} / \mathrm{C}(\%)$} & \multirow{3}{*}{$\mathrm{s} / \mathrm{a}(\%)$} & \multicolumn{6}{|c|}{ Unitcontent $\left(\mathrm{kg} / \mathrm{m}^{3}\right)$} \\
\hline & & & \multirow{2}{*}{ Water W } & \multirow{2}{*}{ Gement $\mathrm{C}$} & \multicolumn{2}{|c|}{ Fine aggregate } & \multirow{2}{*}{$\begin{array}{c}\text { Coarse } \\
\text { aggregate } \mathrm{G}\end{array}$} & \multirow{2}{*}{ Admixtures } \\
\hline & & & & & S1 & $\mathrm{S} 2$ & & \\
\hline $\mathrm{N}$ & 55.0 & 43.1 & 157 & 286 & 561 & 241 & 1073 & 2.86 \\
\hline $\mathrm{BB}$ & 55.0 & 43.4 & 158 & 279 & 567 & 243 & 1073 & 2.97 \\
\hline BT & 60.0 & 46.5 & 164 & 274 & 600 & 275 & 1001 & 2.92 \\
\hline
\end{tabular}

*Cement. Type N: Ordinary Portland cement, BB and BT: Blast-furnace slagcement (Type B).

Table 4 Curing conditions.

\begin{tabular}{|c|c|c|}
\hline Categories & Symbol & Method of curing \\
\hline $\begin{array}{l}\text { Ponded } \\
\text { water }\end{array}$ & W & $\begin{array}{l}\text { Curing for the study of concrete performance standards } \\
\text { - Remove the formwork after } 2 \text { days of material aging and then conduct the standard water curing } \\
\left(20^{\circ} \mathrm{C}\right) \text {. } \\
- \text { After completing curing ( } 28 \text { days), conduct air curing. }\end{array}$ \\
\hline \multirow{3}{*}{ Wet curing } & A1 & \multirow{3}{*}{$\begin{array}{l}\text { Verification of the AC curing effects } \\
\text { - Remove the formwork after } 3 \text { days of material aging ( } 15 \mathrm{~h} \text { for BT) and then conduct AC curing. } \\
\text { - Curing period (N, BB: } 1 / 2 / 3 \text { weeks, BT: } 1 / 2 / 3 \text { months) } \\
\text { - After completing curing, conduct ari curing. }\end{array}$} \\
\hline & $\mathrm{A} 2$ & \\
\hline & A3 & \\
\hline \multirow{2}{*}{$\begin{array}{l}\text { Sheathing } \\
\text { curing (Kind } \\
\text { of } \\
\text { Membrane } \\
\text { Curing) }\end{array}$} & $\mathrm{S}$ & $\begin{array}{l}\text { Curing for actual structures (Curing according to the JSCE curing methods) } \\
\text { - After the curing period described in the specifications, remove the formwork and conduct air curing. } \\
\text { - Curing period (N:5 days, BB,BT: } 7 \text { days) } \\
\text { - After completing curing, conduct air curing. }\end{array}$ \\
\hline & $\mathrm{P}$ & $\begin{array}{l}\text { Curing with a shortened curing period ( } 60 \% \text { of the JSCE curing period) } \\
\text { - Shorten the curing period to } 60 \% \text { of the specifications and conduct curing. } \\
\text { - Curing period (N: } 3 \text { days, BB: } 4.2 \text { days, BT: } 15 \mathrm{~h}) \\
\text { - After completing curing, conduct air curing. }\end{array}$ \\
\hline
\end{tabular}


The relative dynamic modulus of elasticity varies depending on the curing conditions, and this leads to a difference in the concrete performance. The dynamic modulus of elasticity increases in the initial freeze-thaw cycles as the curing period is shortened. This is because hydration of the test specimen, which initially has insufficient hydration, progresses.

The relationship between freeze-thaw cycles and mass change ratio is shown in Fig. 7. The mass at the time of pouring the concrete is used as the standard for the mass change ratio. The mass of test specimens that were not subject to water curing increased because of the absorption of water over 30 cycles, and the mass change ratio was almost the same as with water curing. Therefore, the test specimen can be considered to be water saturated.

Differences in mass change were generated after 30 cycles in accordance with the curing conditions. At 300 cycles, the mass change ratio of sheathing curing $(\mathrm{S}, \mathrm{P})$ was greater than that of water curing and $\mathrm{AC}$ curing (A1 to A3) by $1.5 \%-4.5 \%$. We can thus say that the freeze-thaw resistance of sheathing curing is lower than that of AC curing.

The mass changes linearly after 30 cycles of freeze thaw; therefore, the mass-change speed according to the freeze-thaw cycles is calculated using linear regression.

Fig. 8 shows the relationship between curing period (material age after completing curing) and mass change

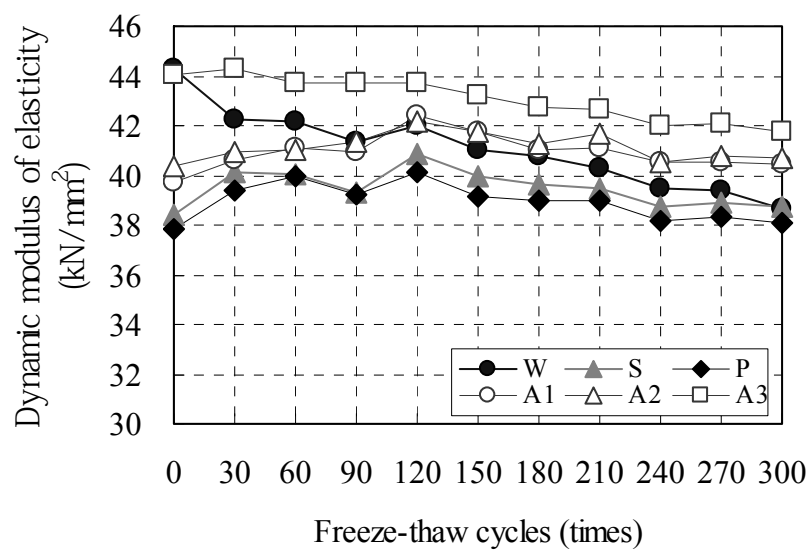

Fig. 6 Relationship between freeze-thaw cycles and dynamic modulus of elasticity.

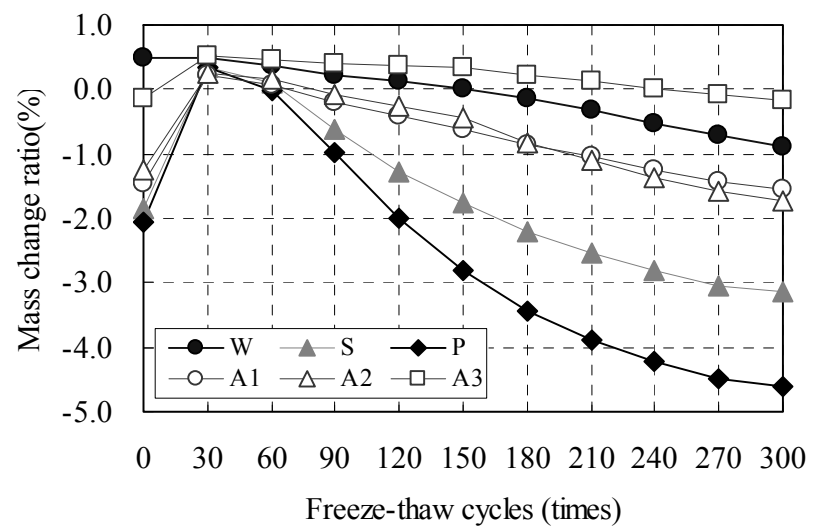

Fig. 7 Relationship between freeze-thaw cycle and mass change ratio.

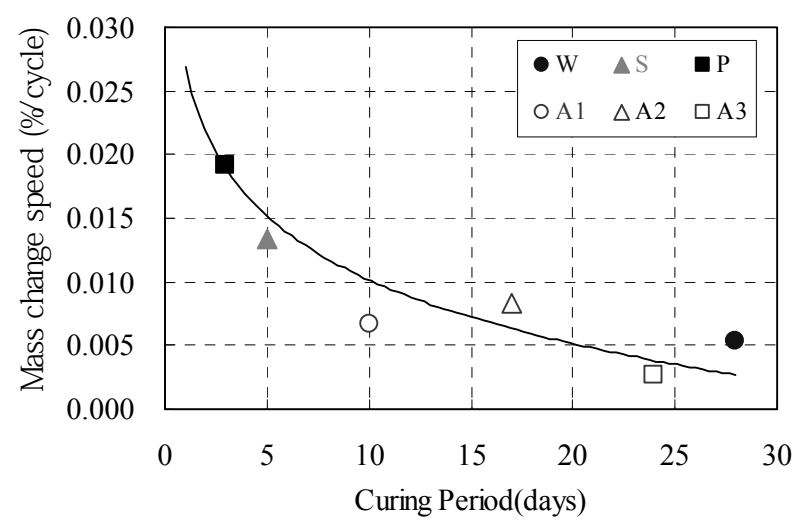

Fig. 8 Relationship between wet curing period and mass change speed.

speed. The mass change speed decreases considerably with increasing curing period. The effect of AC curing is significant, and the mass change decreases at the same rate as when water curing was conducted over 28 days.

\subsection{Effects on Carbonation Resistance}

An accelerated carbonation test was conducted to ascertain the effect on improvement in the quality of the surface layer of concrete by wet curing.

To reproduce the five curing methods (A1 to A3, S, $\mathrm{P})$ shown in Table 4, large test specimens (thickness $0.3 \times$ height $1.2 \times$ length $7.2 \mathrm{~m}$ ) were fabricated. Core specimens were taken from test specimens with a material age of 26 weeks for use in accelerated carbonation tests (JIS A 1153) up to an accelerated period of 13 weeks. 
The carbonation depth caused by the differences in the cements and the curing methods is shown in Fig. 9. Our findings indicate that because the carbonation depth for AC curing is less than that for sheathing curing, the structure of the concrete surface becomes denser due to adequate water absorption.

\subsection{Effect on Pore Structure}

4.4.1 Pore Size Distribution According to Curing Conditions

The compression strength and pore size distribution (mercury intrusion porosimetry) were measured to ascertain the effect of $\mathrm{AC}$ curing on the pore structure of concrete. For this measurement, in order to eliminate the influence of coarse aggregates, a mortar specimen $(\varphi 5 \mathrm{~mm} \times 10 \mathrm{~mm})$ that had been crushed to a size smaller than $5 \mathrm{~mm}$ by wet screening using a $5 \mathrm{~mm}$ sieve was used as a sample.

The measurement results for pore size distribution are shown in Fig. 10. The pore size distribution for each type of cement shifted to the fine-size pore side, becoming a dense pore structure, as the AC curing period was extended.

The pore size from sheathing curing using cement $\mathrm{N}$ and cement BB peaks at around $100 \mathrm{~nm}$ in distribution, and has a rough pore structure compared to AC curing and water curing. Moreover, with the tunnel (BT) specimen, which had an extremely short curing period, the pore size is close to $1000 \mathrm{~nm}$ for formwork curing, and this trend is noticeable.

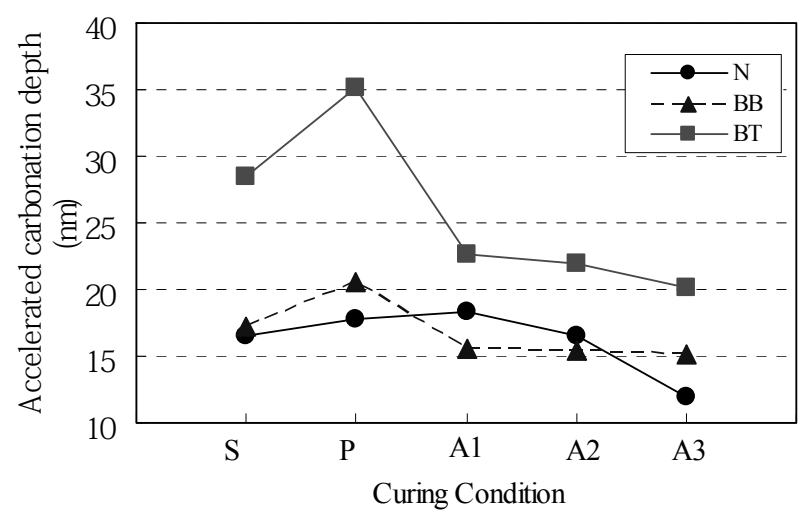

Fig. 9 Comparison of the carbonation depth due to the curing conditions.
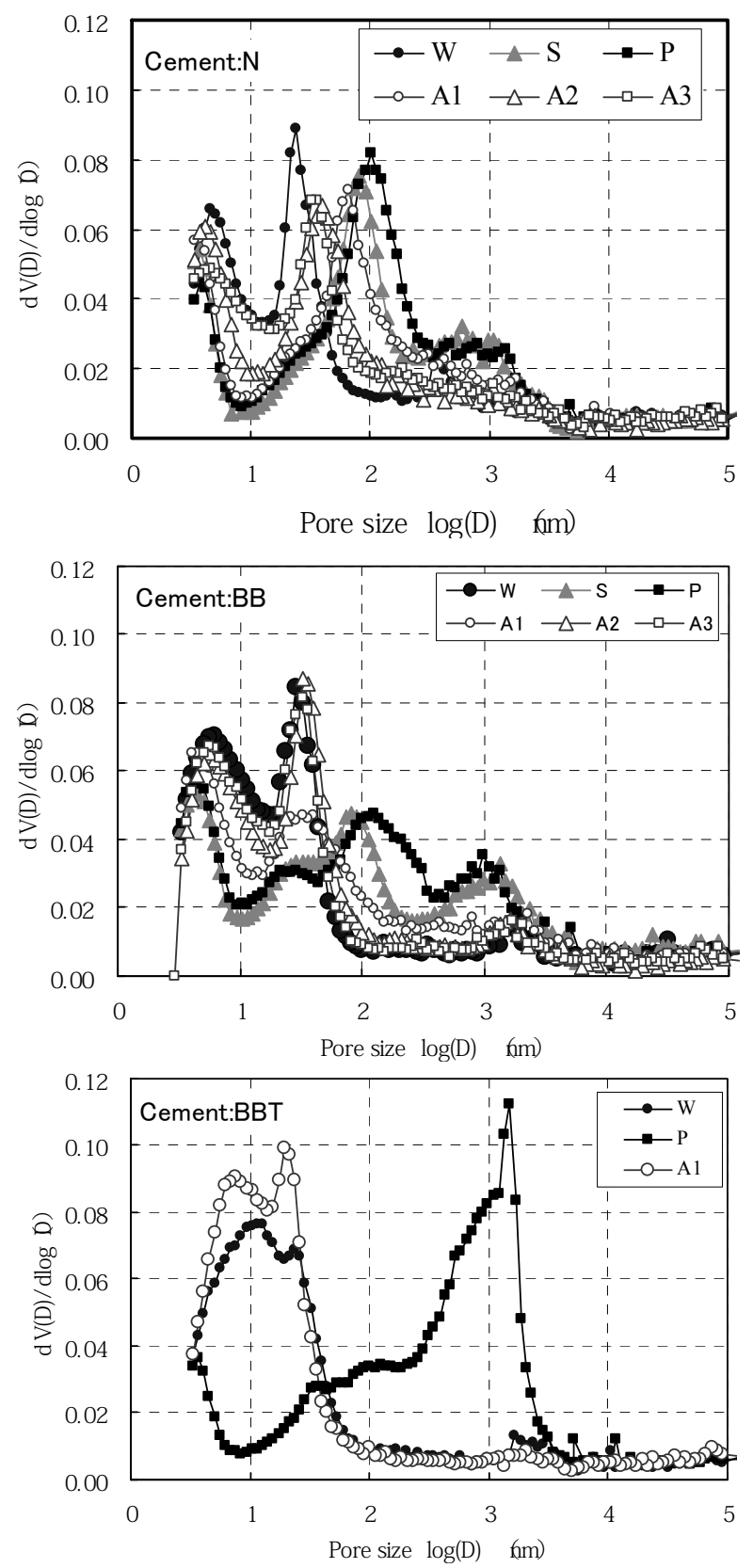

Fig. 10 Pore size distribution.

\subsubsection{Curing Conditions and Pore Volume}

In order to conduct a quantitative evaluation of the differences in pore size distribution according to the different curing conditions and cement types, the effect of curing conditions on the pore volume of a rough-size pore (pore sizes: $10 \mathrm{~nm}$ and $50 \mathrm{~nm}$ ) was studied. The relationships among the curing conditions, the total pore volume, and the pore volume with pore sizes of 10 $\mathrm{nm}$ and $50 \mathrm{~nm}$ or more are shown in Fig. 11. 

Development of the New Wet Curing Method
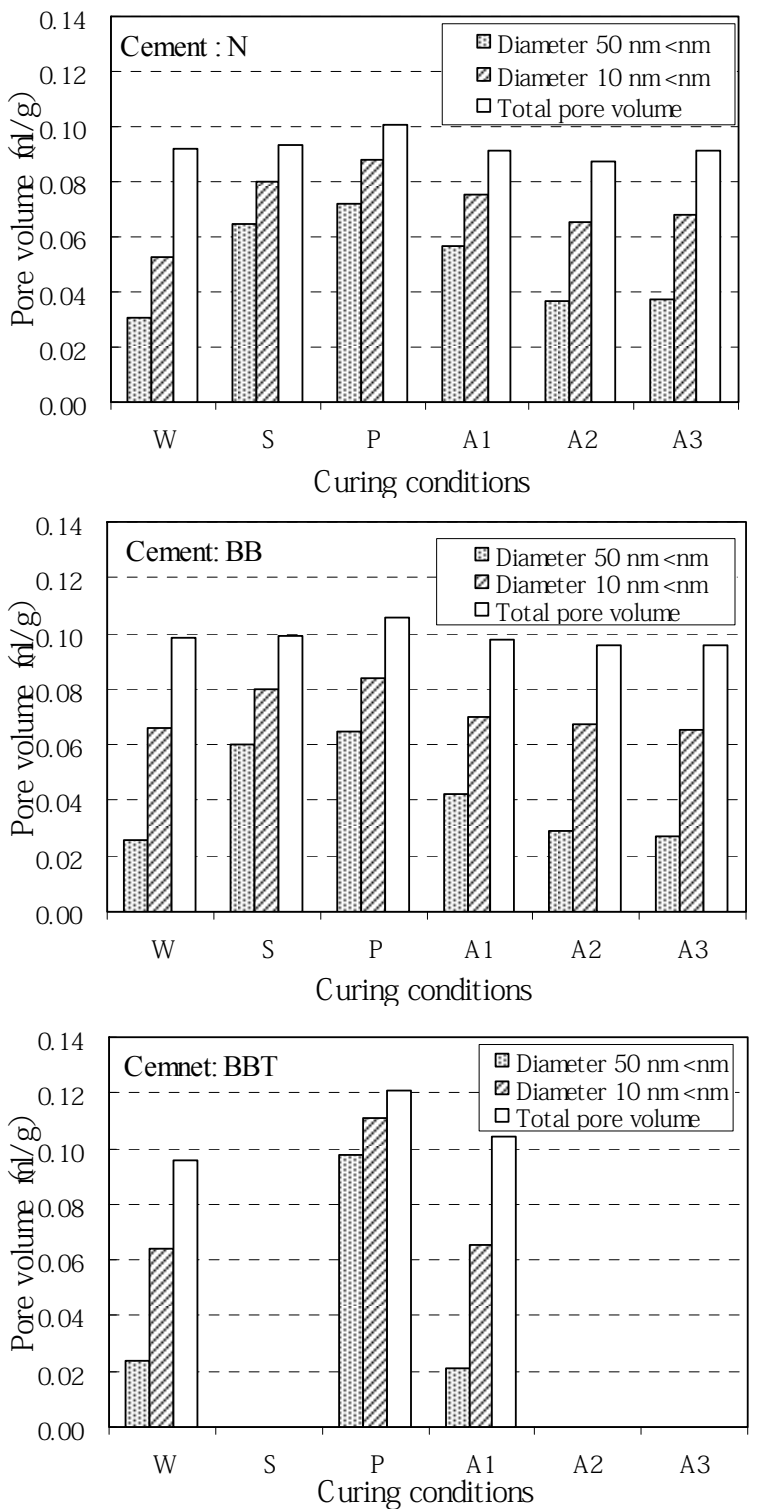

Fig. 11 Relationship between the curing conditions and the pore volume.

The effect of the curing conditions on the total pore volume was minor, but a significant difference occurred in pore volume when the pore size was $10 \mathrm{~nm}$, $50 \mathrm{~nm}$, or more. In particular, the pore volume for the rough-pore size increased when sheathing curing was used, while it clearly decreased for AC curing as the curing period was extended. Therefore, it was found that there is a clear correlation between pore structure, curing period, and curing conditions.

4.4.3 Correlation between Pore Volume for Each Pore Size and Compression Strength
The correlation between the calculated pore volume for each pore size and the compression strength was investigated.

The relationship between pore volume and compression strength is shown in Fig. 12. A correlation with each pore volume is apparent, but the degree of correlation increases for pore volumes with a pore size of $10 \mathrm{~nm}$ or more. It is thought that the differences in the pore structure in accordance with the curing conditions, described earlier, are due to the hydration level.

\section{Examples of On-Site Applications}

\subsection{Construction Example for A Tunnel}

In most examples of lining concrete application, the formwork is removed at an early stage, 12 to $20 \mathrm{~h}$ after the concrete has been poured [10].

Moreover, because of the misunderstanding as to whether the temperature in a tunnel is stable and the ambient conditions are sufficiently wet, special curing is not conducted in some cases of lining concrete curing after the formwork has been removed. However, a study conducted by Baba et al. showed that a humidity of $60 \%-70 \%$ in a tunnel is an inadequate curing environment for concrete [11].

In addition, a tunnel is one of the most difficult structures to be used for wet curing. This is because tunnels have an arch shape and the formwork is removed at an early stage, and therefore, anchors or

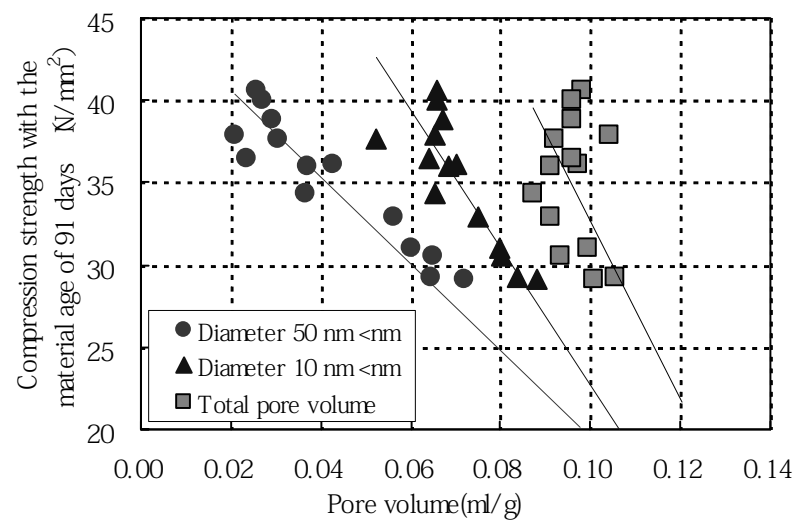

Fig. 12 Relationship between pore volume and compression strength. 

Development of the New Wet Curing Method

other devices for securing curing equipment cannot be used.

With respect to this, we present here some examples of AC applications in tunnel construction. When applied to a tunnel construction, a structure, as shown in Fig. 13, is created by considering the characteristics of the tunnel. In addition, a special carriage for erecting the curing sheet is fabricated, as shown in Fig. 14.

AC application conditions for a two-lane highway tunnel are shown in Fig. 15. The tunnel is $14 \mathrm{~m}$ wide and $9 \mathrm{~m}$ high, and has two lanes. AC curing was conducted for one week as per the JSCE standard.
The lining surface after removing the curing sheet clearly indicates that a layer of water remains on the surface of the concrete, and that sufficient wet curing has been achieved on the surface of the concrete. The lining concrete construction unit was 10.5 meter per span (250 $\mathrm{m}^{2}$ curing area), and a group of six people could lay 1 span of sheet in approximately $1 \mathrm{~h}$.

The measurement results for the temperature and humidity on the surface of the lining concrete are shown in Fig. 16. The surface temperature and humidity of the concrete are stable at approximately $20^{\circ} \mathrm{C}$ and $100 \%$, respectively.

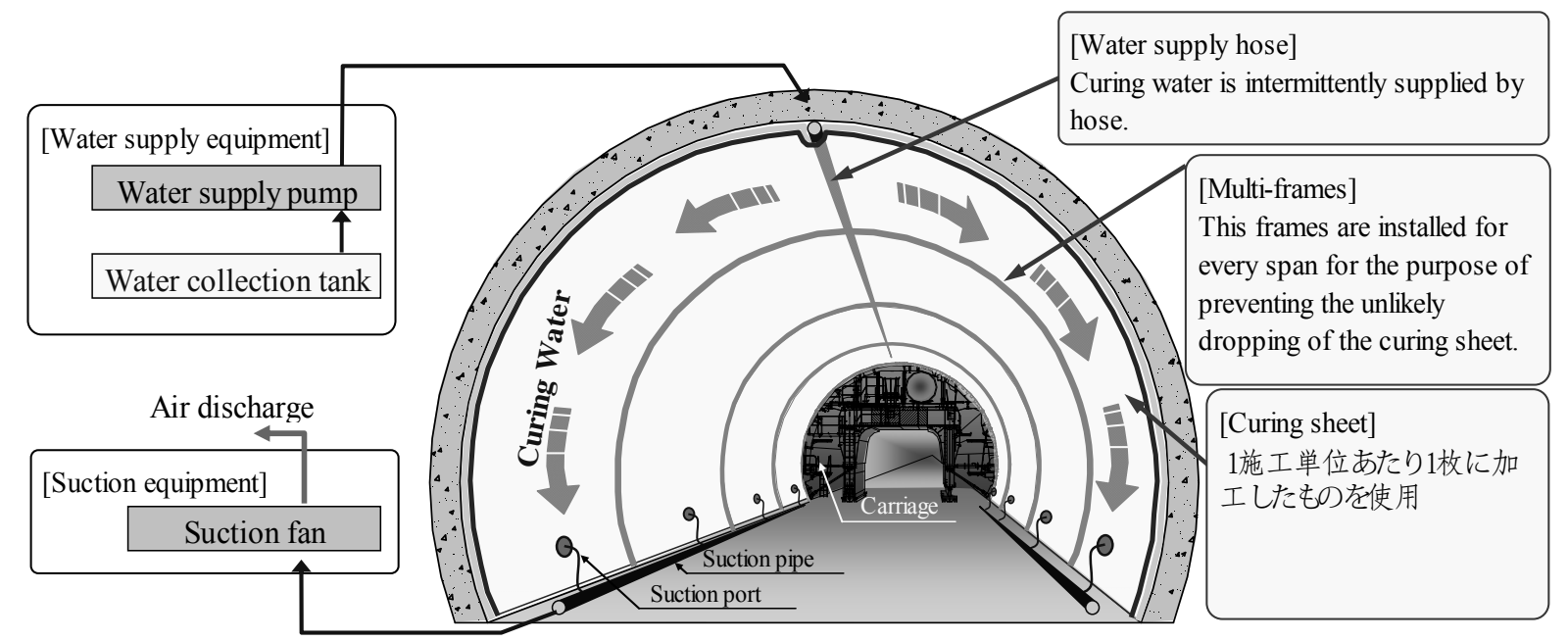

Fig. 13 AC System configuration for a tunnel (example).

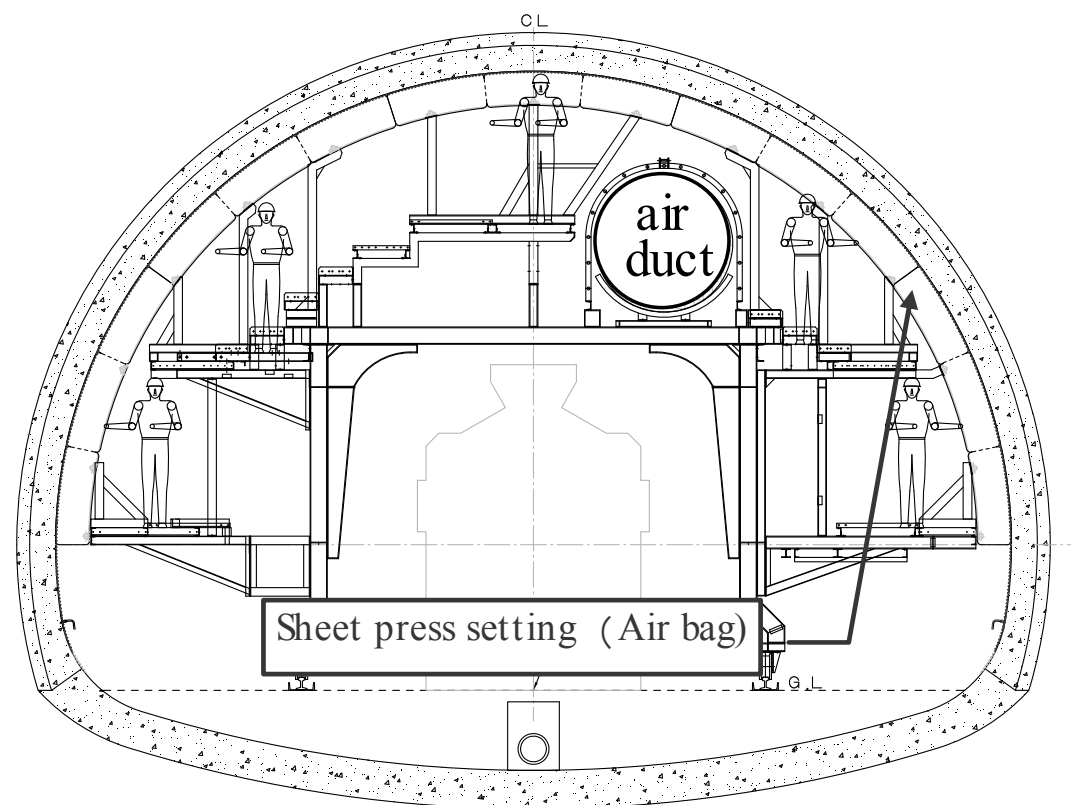

Fig. 14 Schematic of curing sheet erecting carriage. 


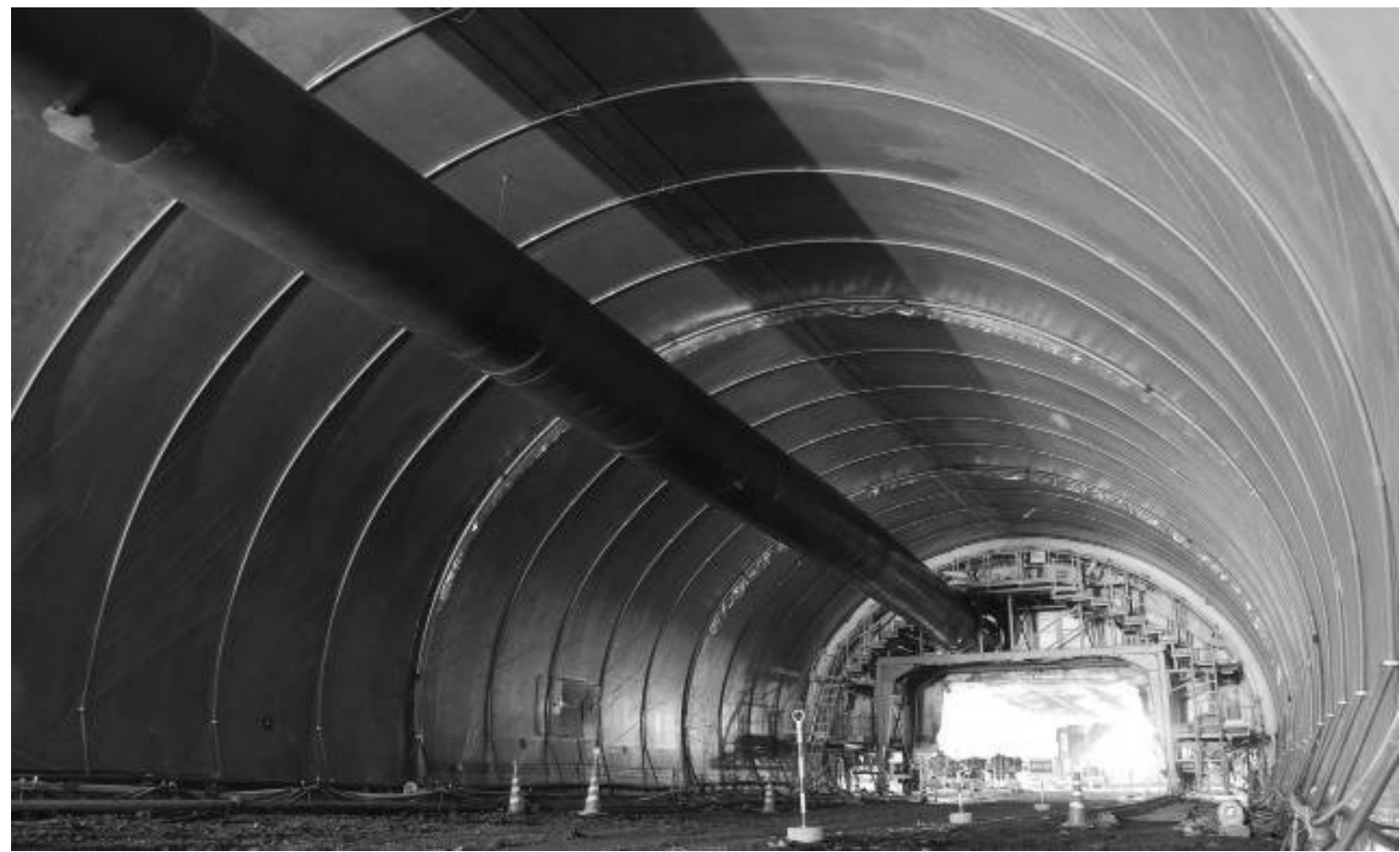

Fig. 15 Erected curing sheet.

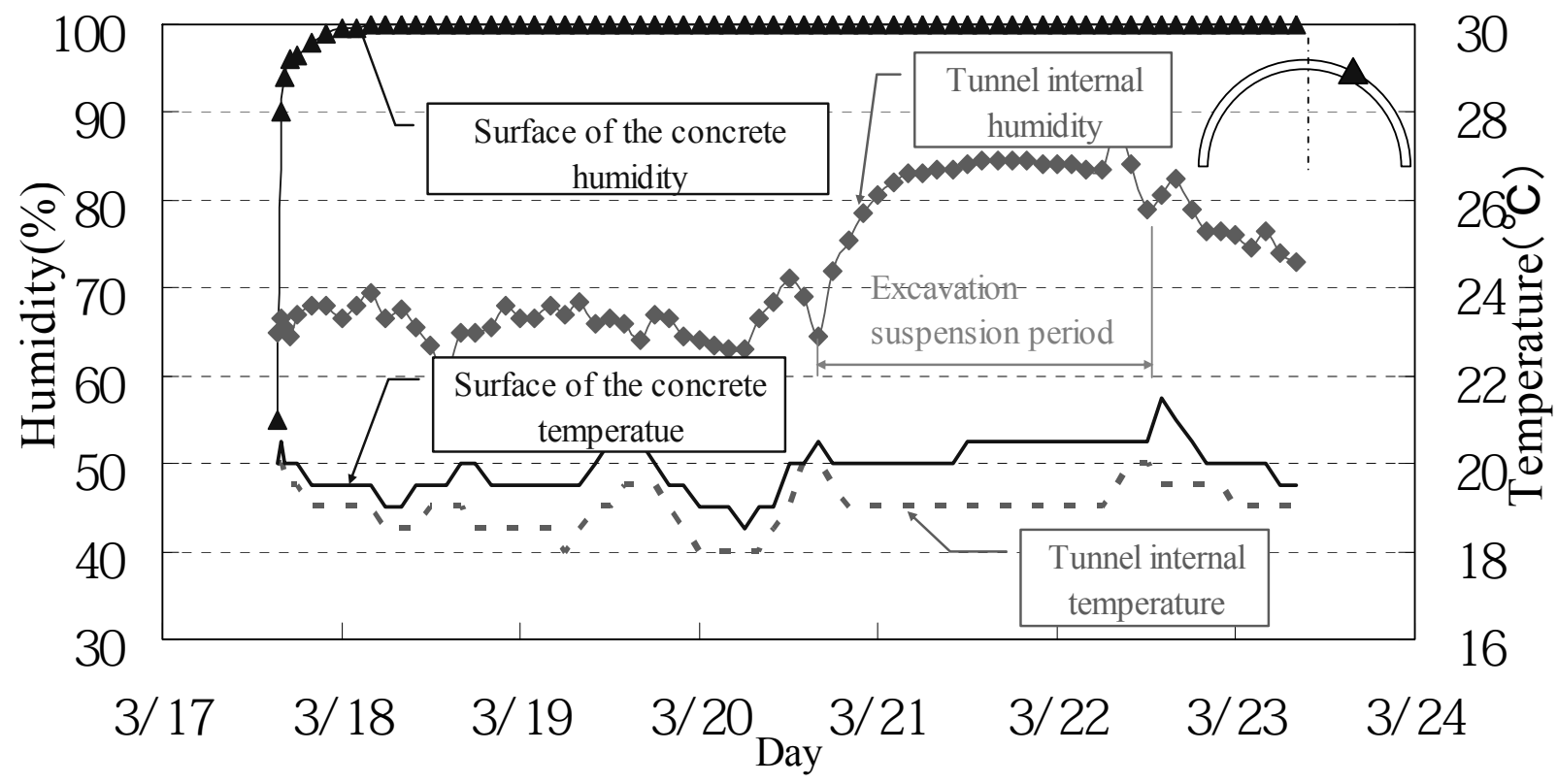

Fig. 16 Temperature and humidity measurement results for concrete lining.

It was ascertained that although the humidity in the tunnel was high, ranging from $80 \%$ to $90 \%$, because the ventilation facility was not in operation while the excavation work was suspended, the humidity in the tunnel was low, at around $60 \%$ to $70 \%$, when the ventilation facility was operating; moreover, the curing environment conditions were poor for the lining concrete.

\subsection{Application Examples for Other Structures}

This construction method can be applied to other structures as well as concrete structures. In Japan, there 
have, up to now, been many examples of application, such as the construction of bridge piers, box culvert walls, prestressed concrete tank walls, external walls of water treatment plants, and retaining side walls. Construction photographs from application examples are shown in Figs. 17-18.

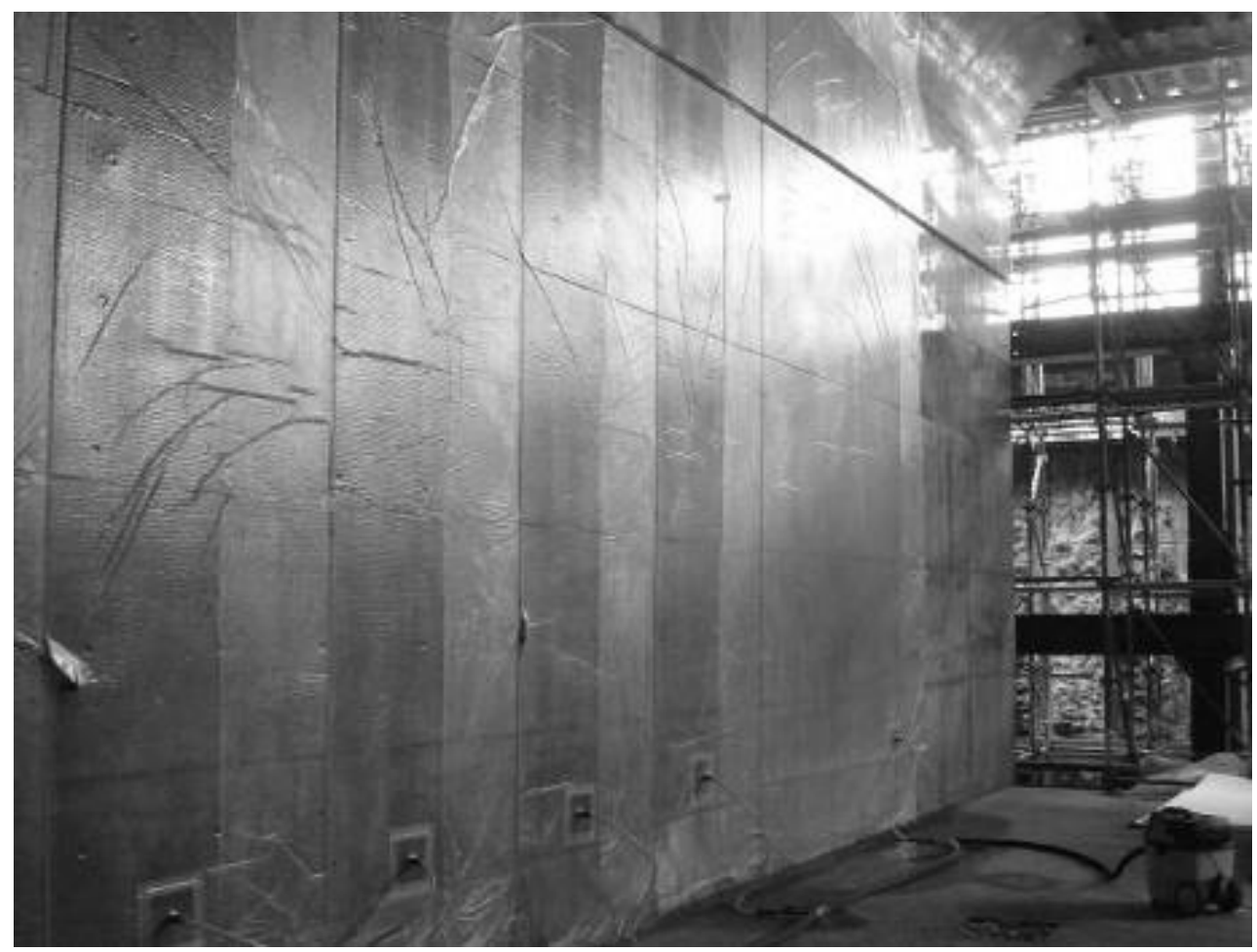

Fig. 17 Application to a box culvert wall.

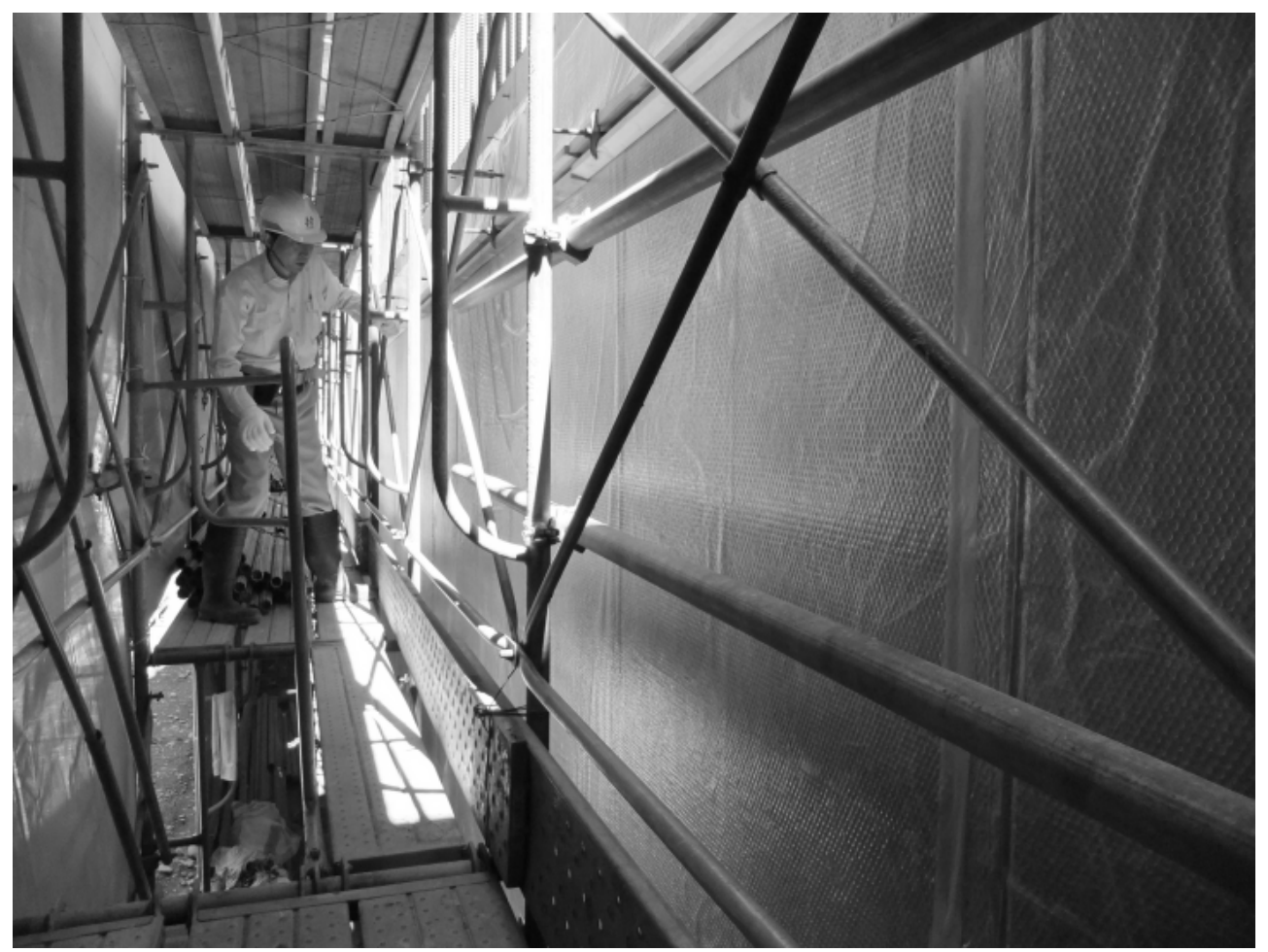

Fig. 18 Application to a wall at a water-treatment plant. 


\section{Conclusion}

In this study, the effects of $\mathrm{AC}$ wet curing on improving concrete durability were ascertained. The findings from this study are described below.

Compared to sheathing curing, wet curing improved freeze-thaw resistance and carbonation resistance, as well as the durability of the concrete.

By applying wet curing, which provides adequate moisture, the concrete becomes denser and the pore structure becomes the same as that obtained with water curing.

It was found that the AC system can be applied to, and wet curing correctly conducted, even to sections on which it is generally difficult to conduct wet curing, such as vertical walls and arch structures, and that when applied, it exhibits superior practicality.

On the basis of the abovementioned findings, we can state that a dense concrete surface can be achieved and long-term durability can be improved by removing the formwork immediately after a strength sufficient to allow the removal of the formwork has been ensured, and by then conducting AC curing.

\section{References}

[1] Y. Furukawa, M. Suzuki and Y. Mitani, Development of moisture curing system for tunnel concrete lining, in: 12th ISRM International Congress on Rock Mechanics, 2011, 11, pp. 1675-1678

[2] ACI Committee Reports: Guide to Curing Concrete, Aug. 2001

[3] ACI Committee Reports: Standard Specification for Curing Concrete, 1998.4.

[4] Standard Specifications for Concrete Structures-2007, Materials and Construction, JSCE, 2007, pp. 126-129.

[5] Japanese Architectural Standard Specification Reinforced Concrete Work, JASS5, Architectural Institute of Japan, 2009, pp. 270-277.

[6] Architectural Institute of Japan, Recommendation for Practice of Hot Weather Concreting, Sep. 2000, pp. 106-116.

[7] A. M. Neville, Properties of concrete, Fourth and Final Edition Standards updated to 2002, pp. 323-326.

[8] K. Fukudome, Y. Furukawa and A. Shono, Study on the Estimation Method of Strength Developmentof Concrete Under Various Moisture Curing Conditions, Journal of Japan Society of Civil Engineers, Ser. E2, Materials and Concrete Structures 67 (1) (2011) 18-27.

[9] S. Okazaki, T. Yagi, T. Kishi and T. Yajima, Difference of Sensitivity Due to Curing Condition on Strength and Permeability, Cement Science and Concrete Technology 60 (2006) 227-234.

[10] Standard Specifications for Tunneling-2006, Mountain Tunnels, JSCE, 2006, pp. 94-96.

[11] Koji Baba, Study on the tunnel environment under construction and humidity change of lining concrete, JSCE 60 (742) (2009) 27-35. 